\title{
An investigation into the perceptions of business stakeholders on the benefits of enterprise architecture: The case of Telkom SA
}

\author{
S.M. Lehong* \\ School of Business Leadership, PO Box 392, \\ UNISA 0003, Republic of South Africa \\ lehongsm@gmail.com

\section{E. Dube} \\ Council for Scientific and Industrial Research (CSIR) \\ Modelling and Digital Science (MDS), Pretoria 0001, \\ Republic of South Africa \\ eDube1@csir.co.za

\section{G. Angelopoulos} \\ CENTRUM Católica, Pontificia Universidad Católica de; Perú, \\ Calle Alomia Robles 125-129, Urb. Los Alamos de Monterrico, \\ Surco, Lima 33, Perú \\ gangelopulo@pucp.edu.pe
}

\begin{abstract}
This study identifies the perceived benefits of Enterprise Architecture (EA) among business stakeholders who are aware of EA but are not specialists in the field of ICT, and proposes a clearly differentiated and comprehensive cluster of stakeholder groups based on these perceptions. It provides an understanding of the benefits of EA from the perspective of business beneficiaries, not the perspective of its practitioners.
\end{abstract}

The study was conducted using Q-methodology, which was developed specifically to uncover subjective perceptions and preferences. Q-methodology correlates people in respect of their perception of a sample of tests, and is particularly useful in bridging the sharp dichotomy between qualitative and quantitative methodologies.

The research identifies and describes 9 EA stakeholder types: Transformational Task-Driven Strategist, Universal RiskTolerant Pragmatist, Evolutionary Reuse Overseer, Technology Leverager, Simplicity Valuer, IT Commoditiser, Operational Stability Maintainer, Organisational Change Manager, and Siloed Product Manager. The study demonstrates an increasing understanding of EA benefits, and points to strategies that may be deployed when engaging each stakeholder class.

*To whom all correspondence should be addressed.

\section{Introduction}

This study delineates the benefits of Enterprise Architecture (EA) to organisations, identifies dominant perceptions of the benefits of EA amongst a particular company's business stakeholders, and develops a typology of business stakeholder sub-sections as they relate to the perception of EA benefits. The focus of the study is the identification of the range of attitudes that exist amongst a particular set of business stakeholders towards EA benefits.

Attitudes are generally viewed as a person's subjective evaluation of a particular topic (Wilkins, 2003). In order to identify attitudes towards EA, a methodology that is capable of identifying the subjectivity and complex constituent viewpoints inherent in attitudes must be utilised. In this study Q-methodology has been used for the purpose.

Q-methodology was developed by William Stephenson in 1935 to uncover people's subjective perceptions of any issue towards which different points-of-view can be expressed. Its prime emphasis is on exploration rather than hypothesis testing. The focus of Q-methodology is the internal reference framework used by an individual to make decisions about the relative significance of individual stimuli (Sexton, Snyder, Wadsworth, Jardine \& Ernest, 1998). "Q-methodology is based on an individual participant's viewpoint and not the researcher's viewpoint, each of the responses is taken as valid and as a valuable source of knowledge" (Amin, 2000: 411).

This study provides an understanding of the benefits of EA from the perspective of business stakeholders and the segments that they fall into. The assumption that underlies segmentation is that specific groups of stakeholders can be clustered into segments according to their unique needs, behaviours and other relevant characteristics (Best, 2005). Segmentation can ensure that appropriate communication and EA products are developed for particular stakeholder groups (Van der Raadt, Schouten \& Van Vliet, 2008). "The 
value proposition for a segment should be built around benefits sought by the target stakeholder grouping" (Best, 2005: 147).

The study was undertaken at Telkom South Africa, a company listed on the Johannesburg Securities Exchange, amongst non-ICT business stakeholders with an awareness of EA. Telkom is Africa's largest integrated communications company, providing integrated communications solutions to a wide range of customers. The company's stated objective is to become world-class. At the time of this study and to this end, the company has undergone a transformation process driven by the following thrusts of strategic intent: to offer customers enhanced bundled packages and tailored calling plans; to use fixed-mobile capability as a platform for future growth; to utilise the strength and reliability of its infrastructure to bring high-quality broadband products to market; and to become a Pan-African integrated service provider (Telkom, 2010). Telkom's intentions cannot be achieved without undergoing a comprehensive transformation exercise that constitutes an overhaul of its products and services and the dependent Information and Communications Technologies, including EA, that support a forward-looking business model.

\section{Stakeholder perception of enterprise architecture}

Typical modern enterprise is continuously evolving in order to adapt to an ever changing external environment of, amongst others, the market, customer, competition, regulatory landscape and new market segments (Strano \& Rehmani, 2007; Zachman, 1987). This has created tremendous challenges for business leaders and has led, in response, to the implementation of divergent goals by many business units within individual enterprises (Zachman, 1987). The EA role was initially introduced to address this specific challenge.

EA is still a maturing discipline with varied views of what it entails. Weill and Ross (2009: 91) define Enterprise Architecture as "the design of the firm's digitised platform." Van der Raadt and Van Vliet (2008) define it as a holistic view of the organisation's current state, a clear description of the target situation, and a roadmap to an integrated, well structured organisation. Hilliard (2000: 10) on the other hand defines it as "the fundamental organisation of a system embodied in its components, their relationships to each other and to the environment and the principles guiding its design and evolution." It is clear that a universally acceptable definition of the discipline is some way off, and still a matter of debate amongst practitioners and academics. For the purpose of this study we stay clear of the argument around definition and focus on what enterprise architects should provide to the organisation. We have adopted Kappelman's (2010: 2) view that "EA provides a clear and comprehensive picture of an entity, whether an organisation or a functional or mission area that cuts across more than one organisation... the end object is not to build and run information systems. The end object is to engineer and manufacture the enterprise." In effect, therefore, EA provides a holistic set of descriptions about the enterprise over time.
Chung, Song, Song and Subramanian (2009) classify Enterprise Architecture benefits as ICT-specific and business-specific. It appears that most EA benefits research has been designed to describe the typical pattern and content of observed EA initiatives, not to directly answer the question of which EA benefits are necessary and effective. Uncovering what most EA initiatives identify as EA benefits does not tell us how these benefits were derived or whether business stakeholders consider them essential or beneficial. Therefore, of the many EA benefits that are proffered by the ICT profession, many may not be perceived as the most effective by other business stakeholders - such perception has scarcely been tested. Most research identifies and attempts to resolve EA implementation issues from a technical perspective (Lindström, Johnston, Johansson, Ekstedt \& Simonsson, 2006). In such research the focus is primarily on the production of architectural artefacts and the quality and maintenance of those artefacts, with little focus on stakeholder-related challenges.

Kluge, Dietzsch and Rosemann (2006), however, find that stakeholder-orientation is a necessary condition of EA value and that EA initiatives have to be stakeholder-oriented for them to realise any sort of success. As for the challenge of classifying EA stakeholders by type, there is evidence of a growing awareness that EA stakeholders are not homogeneous and that the categories that have been proposed are still very broad and non-specific (Van der Raadt et al., 2008).

\section{Q-Methodology}

Nonaka and Toyama (2005) have intimated that new knowledge is created through a circular process where subjective tacit knowledge held by an individual is externalised into objective explicit knowledge which is then used and embodied by individuals to enrich their subjective tacit knowledge. Gremy, Fessler and Bonnin (1999) argue that in any information system that includes human subjects as part of the system, any evaluation of the system must take into account those subjects' feelings, reactions, and behaviour. Instead of treating knowledge as objective and static truth, Nonaka and Toyama (2005) argue that knowledge is created through a dynamic interaction between subjectivity and objectivity. Viewing the knowledgecreation process in this manner implies that the value of subjectivity in knowledge expansion is immeasurable. It further means that in attempting to understand that process and the knowledge thus created we should strive to uncover its subjective dimension as effectively as possible.

The methodology used in this study is Q-methodology, which "holds special promise for those seeking to make more intelligible and rigorous the study of human subjectivity" (McKeown \& Thomas, 1988: 12). According to Brown (1993), Q-methodology provides a foundation for the systematic study of subjectivity, a person's viewpoint, opinion, beliefs, attributes, and the like. Q-methodology was developed as a variation of factor analysis by William Stephenson in the 1930's following his work in factor analysis as a student of Charles Spearman and colleague of Cyril Burt. Q-methodology is, however, not well known and cannot be considered a mainstream methodology 
(Angelopulo, 2009), but has nonetheless been used in behavioural research in fields including politics, psychology, sociology, marketing, and more recently Information and Communication Technology.

Q-methodology is based on the two-fold premise that subjective points-of-view are communicable and always advanced from a position of self-reference. It therefore follows that subjective communication is amenable to objective analysis and understanding provided that the analytical means for studying such communication does not in the process destroy or alter its self-referent properties (McKeown \& Thomas, 1988). Rather than administering tests to a sample of people, Q-methodology "administers" people to a sample of test items. Q-methodology attains validity by posing many questions to a few subjects rather than by posing a few questions to many people (Kowert, 1996).

Q-methodology utilises Q-samples and Q-sorting as data gathering instruments and Q-factor analysis as its statistical data analysis tool. The successful application of Qmethodology requires a research topic, a research question and a list of statements regarding the research topic. The methodology requires a specific level of rigour, process and method. In the succeeding sub-section these are discussed.

Q-methodology is typically used where there are fewer persons than tests to be correlated, and when it appears that relations among persons could be interpreted better than relations among tests. It uncovers the nature of the correlation among persons as opposed to the extent of the correlation, and focuses on interrelations among persons with respect to a population of tests. The research process comprises a number of steps: collection of opinion statements, development of representative statements, rank ordering of the statements, sorting of statements with a Qsort, factor analysis and interpretation.

\section{Process and application}

The process begins with the collection of opinion statements. The collected set of opinion statements is referred to as the Concourse, which can be derived from a variety of sources that may include interviews, newspaper articles, academic articles and personal interviews. The concourse is ideally a comprehensive set of opinions on the topic under consideration. From this broad and often very extensive set of opinions, a smaller, representative, and more manageable set called the Q-sample is derived. The smaller Q-sample is drawn from the concourse to represent the main themes contained in the concourse and by extension, the topic of discourse (Amin, 2000; Steelman \& Maguire, 1999).

The sample of statements in the Q-sample is developed to represent the topic of discourse. In the process the raw data is redefined, clarified, and combined into more meaningful statements. It should be noted that one of the most important aspects of this form of research is the identification of the tacit, underlying criteria and perceptions that people use to consider an issue - the opinion statements themselves are of secondary importance (Donner, 2001). The Q-sample is then generally piloted with a small group that may represent the participants, a sample of users, or experts on the topic under consideration. The pilot test ensures that breadth and comprehensiveness are achieved in order to maximise confidence that the major factors at issue have been manifested in the set of items comprising the Q-sample (Van Exel \& De Graaf, 2005).

The Q-sample is then submitted for assessment to the final group of participants. These participants (known as the Psample or more commonly the 'person sample') are selected according to the principles of theoretical sampling as opposed to more commonly used sampling techniques. The researcher attempts to include among the participants an array that will represent the full spectrum of perceptions that are held on the topic under consideration. It is less important to select participants according to the degree to which they represent the population or its demographics. This is due to the fact that the methodology is based on the principle of identifying person types: "the subjects must be chosen for the study depending on known characteristics that they possess" (Frederick, 1999: 14).

Q-sorting, as defined by Brown (1980) is the means whereby data are obtained for factoring. The Q-sorting process is achieved by participants ordering the Q-sample statements in a ranked matrix according to some pre-defined instruction (e.g. most important to least important). Participants simply rank statements in accordance with how they view the issue at hand. The ranked statements of each participant is termed a Q-sort. Due to the fact that the same opinion statements are assessed in the same assessment format by different participants who more than likely have different perspectives, more rigour can be obtained in the comparison of their subjective preferences.

There are two primary conditions of instructions which can be followed in the Q-sort process: forced-choice and freesort conditions of instruction. The forced-choice condition of instruction requires participants to sort the Q-sample statements according to a pre-defined matrix (McKeown \& Thomas, 1988). Participants determine the meaning of their own sort as they are free to place any of the Q-sample statements at any position across the continuum. The restriction on the forced-choice condition of instruction is that the range and number of statements allocated are predetermined by the researcher (Table 1).

The free-sort condition of instruction, on the other hand, imposes no restrictions on the participants (see Table 2 below as an example). Brown (1980) is of the opinion that when participants are not knowledgeable about the subject under consideration, the free-sort condition of instruction is suitable. He further argues that in such a study, participants are not expected to have opinions about most statements and as such more freedom is given on the Q-sort. 
Table 1: Forced-choice condition of instruction

$$
\begin{array}{lllllllllll}
-5 & -4 & -3 & -2 & -1 & 0 & 1 & 2 & 3 & 4 & 5
\end{array}
$$

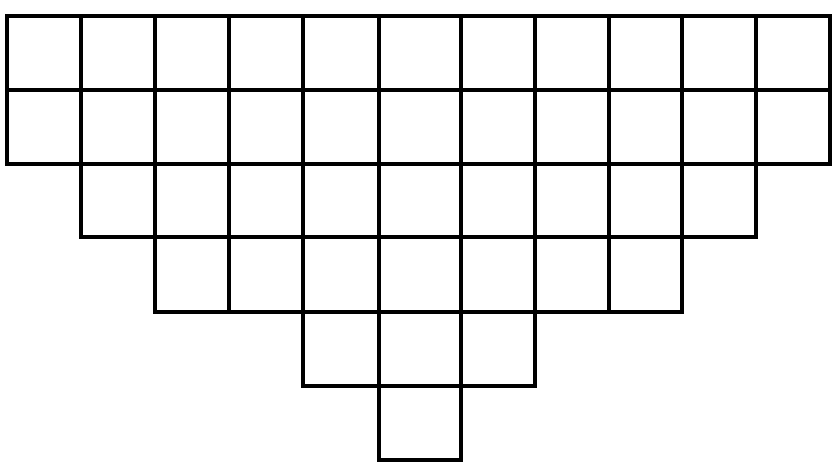

Table 2: Free-sort condition of instruction

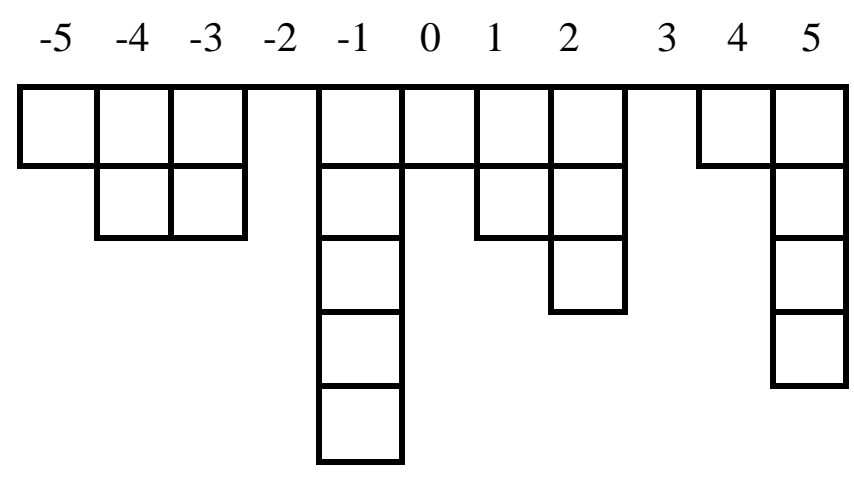

Once all participants have completed their Q-sorts, the arrangement of their statements is formally compared by means of factor analysis. Factor analysis reveals deep structures implicit in subjectivity, but about which neither the subject nor the investigator may be aware (Amin, 2000). Factor analysis is a collection of methods used to examine how underlying constructs influence the responses on a number of measured variables (DeCoster, 1998). The factor analysis used in Q-methodology differs from other variations of factor analysis because it correlates people the participants - as opposed to variables, as is the case in normal factor analysis. Q-based factor analysis factors subjects and attempts to identify different types of people, depending on their responses to certain variables (Frederick, 1999).

In this study the forced-choice condition of instruction was selected in order to crystallise the subjective hierarchies that govern stakeholder perceptions of EA benefits. The Qsample was drawn from a number of sources. Statements were derived from Niemi's (2006) research on EA benefits, adapted to reflect a number of perspectives that are more recent than those expressed in Niemi's original research (refer to Table 3); and from Ross (2003), Strano and Rehmani (2007), Van der Raadt et al. (2008), Jonkers, Lankhorst, Ter Doest, Arbab, Bosma and Wieringa (2006), Plazaola, Flores, Vargas and Ekstedt (2008), Pereira and Sousa (2005), Buchanan and Soley (2002), Ross, Weill and Robertson (2006), Malan, Bredemeyer, Krishnan and Table 3: Enterprise architecture benefits
Lafrenz (2006), Chung et al. (2009), Cardwell (2008), Kamogawa and Okada (2009), Ross and Weill (2005), Kluge et al. (2006), Liimatainen (2008), Harris (2008), De Vries and Van Rensburg (2008), and Harmon (2005). A number of benefits have also been drawn from general, nonspecific discussion with EA practitioners and EA experts. These appear to be commonly held but are unidentified in the literature, and are indicated as "Expert Opinion".

The analysis of the Q-sort matrix was undertaken with the PCQ for Windows software package. The factor loading of each Q-sort represents its correlation with the factor. Positive factor scores indicate agreement with the statement and are therefore viewed as an important benefit of Enterprise Architecture whereas negative factor scores indicate disagreement with the importance of the benefit. The higher the score (positive or negative), the more strongly the benefit is deemed important, and vice versa.

Each of the derived factors has at least one defining sort, which indicates the responses of the participants who loaded heavily on the factor. All factors are created by ranking the entire sample and not just the participants who most identify with the factor.

Of the 23 participants in the study 16 were female and 7 male, the average years of service in their current organisation was 6,4 , and all had at least a 3-year diploma qualification. Roughly $60 \%$ were in management positions.

The nine derived factors accounted for $58 \%$ of the variance, with 17 participants' sorts being accounted for in these factors. The naming of the factors was meant to capture the core characteristics of each factor. Loading significance was set at equal to or greater than 0,40 .

Four participants (17,4\% of participants) loaded on Factor 1. The factor has an eigenvalue of 3,67 and accounts for $16 \%$ of the total variance (see Table 5). The loadings on Factor 1 have the second highest values, all being above, 70 .

Two of the participants (8,7\% of participants), $9 \%$ of the total variance and an eigenvalue of 2,02 loaded on Factor 2 (see Table 6). The loadings on Factor 2 have the highest values, all above, 80 .

Only one participant $(4,35 \%$ of participants $)$ loaded significantly on Factor 3, with 5\% of the total variance and an eigenvalue of 1,25 (see Table 7). This factor is negatively loaded and as a result the statements were switched in order to identify the factor's true values.

Two $(8,7 \%)$ of the participants loaded on Factor 4 (see Table 8), with $4 \%$ of the variance and an eigenvalue of 0,87 .

One participant $(4,35 \%)$ loaded on Factor 5 (see Table 9) with $4 \%$ of the total variance and an eigenvalue of 0,84

Two of the participants $(8,7 \%)$ loaded on Factor 6 (see Table 10), with $7 \%$ of the variance and an eigenvalue of 1,65 . 


\begin{tabular}{|c|c|}
\hline EA Benefits Statement & Sources \\
\hline 1. Shortened cycle times. & Niemi (2006); Van der Raadt \& VVliet (2008) \\
\hline 2. Improved business-IT alignment. & $\begin{array}{l}\text { Niemi (2006); Brown (2004); Malan, Bredemeyer, Krishnan \& Lafrenz } \\
\text { (2006); Plazaola, Flores, Vargas \& Ekstedt (2008); Buchanan \& Soley (2002); } \\
\text { Pereira \& Sousa (2005); Matthee, Tobin \& Van der Merwe (2006) }\end{array}$ \\
\hline 3. Improved risk management. & Niemi (2006); Ross \& Weill (2006); Van der Raadt \& Van Vliet (2008) \\
\hline 4. Provides a holistic view of the enterprise. & Niemi (2006); Harmon (2005) \\
\hline 5. Improved communication. & Niemi (2006) \\
\hline 6. Increased economies of scale. & Niemi (2006) \\
\hline 7. Improved change management. & $\begin{array}{l}\text { Niemi (2006); Kamogawa \& Okada (2009); Van der Raadt \& Van Vliet } \\
\text { (2008); Matthee, Tobin \& Van der Merwe (2006) }\end{array}$ \\
\hline 8. Increased quality. & \multirow{3}{*}{ Niemi (2006) } \\
\hline 9. Increased market value. & \\
\hline 10. Improved alignment with partners. & \\
\hline 11. Increased interoperability and integration. & \multirow[t]{2}{*}{ Niemi (2006); Ross, Weill \& Robertson (2006) } \\
\hline 12. Increased standardisation. & \\
\hline 13. Improved business processes. & Niemi (2006); Brown (2004) \\
\hline 14. Improved alignment to business strategy. & Niemi (2006); Harris (2008) \\
\hline 15. Improved asset management. & \multirow{3}{*}{ Niemi (2006) } \\
\hline 16. Evolutionary EA development \& governance. & \\
\hline 17. Improved customer orientation. & \\
\hline 18. Reduced complexity. & Niemi (2006); Chung, Song, Song \& Subbramanian (2009) \\
\hline 19. Reduced costs. & Niemi (2006); Ross \& Weill (2006); Liimatainen (2008) \\
\hline 20. Increased stability. & Niemi (2006) \\
\hline 21. Increased reusability. & Niemi (2006), Brown (2004); Harris (2008) \\
\hline 22. Increased efficiency. & Niemi (2006); Kamogawa \& Okada (2009) \\
\hline 23. Improved strategic agility. & $\begin{array}{l}\text { Niemi (2006); Ross \& Weill (2006); Kamogawa \& Okada (2009); Brown } \\
\text { (2004); Chung, Song, Song \& Subbramanian (2009) }\end{array}$ \\
\hline 24. Improved staff management. & Niemi (2006) \\
\hline 25. Improved management of IT investment. & Niemi (2006); Harris (2008) \\
\hline 26. Improved decision making. & Niemi (2006); Chung, Song, Song \& Subbramanian (2009) \\
\hline 27. Improved innovation. & Niemi (2006) \\
\hline 28. Improved IT governance. & Harris (2008) \\
\hline 29. Improving integration of mergers and acquisitions. & Liimatainen (2008); Matthee, Tobin \& van der Merwe (2006) \\
\hline 30. Compliance to legislation. & $\begin{array}{l}\text { Cardwell (2008); Malan, Bredemeyer, Krishnan \& Lafrenz (2006); Harmon } \\
\text { (2005); Jonkers, Lankhorst, Ter Doest, Arbab, Bosma \& Wieringa (2006) }\end{array}$ \\
\hline 31. Improve business use of technology. & Kamogawa \& Okada (2009) \\
\hline 32. Shared business platforms. & Ross \& Weill (2006); Ross, Weill \& Robertson (2006) \\
\hline 33. Managerial satisfaction. & Ross \& Weill (2006); Van der Raadt \& van Vliet (2008) \\
\hline 34. Accelerate IT system implementation. & Expert Opinion \\
\hline 35. Readily available documentation of the enterprise. & Brown (2004) \\
\hline 36. Ability to unify and integrate data across the enterprise. & Brown (2004); Ross, Weill \& Robertson (2006) \\
\hline 37. Improved IT visibility. & Chung, Song, Song \& Subbramanian (2009) \\
\hline 38. Reduce the impact that staff turnover has on business. & Chung, Song, Song \& Subbramanian (2009) \\
\hline 39. Closer partnership between business and IT. & \multirow{4}{*}{ Expert Opinion } \\
\hline 40. Enable business intelligence. & \\
\hline 41. To keep the business from disintegrating. & \\
\hline 42. Improve IT Security. & \\
\hline
\end{tabular}

Table 4: Factor variance $\&$ eigenvalues

\begin{tabular}{lcccccccccc}
\hline Factors & 1 & 2 & 3 & 4 & 5 & 6 & 7 & 8 & 9 & Totals \\
Eigens & 3,67 & 2,02 & 1,25 & 0,87 & 0,84 & 1,65 & 1,33 & 0,82 & 0,68 & 13,13 \\
$\%$ Variance & 16 & 9 & 5 & 4 & 4 & 7 & 6 & 4 & 3 & 58 \\
\hline
\end{tabular}


Table 5: Factor 1. Transformational task-driven strategist, key items

\begin{tabular}{|c|c|c|c|c|c|c|c|c|c|c|c|}
\hline Statement & F1 & $\mathrm{F} 2$ & F3 & F4 & F5 & F6 & F7 & F8 & F9 & $\begin{array}{c}\text { Total No. } \\
\text { Respondents }\end{array}$ & $\%$ \\
\hline Statement 4: Provides a holistic view of the enterprise & +5 & +5 & +5 & -1 & +1 & +3 & +4 & -4 & +5 & 10 & $43,50 \%$ \\
\hline Statement 14: Improved alignment to business strategy & +5 & -1 & -3 & -2 & 0 & +5 & -2 & 0 & +2 & 6 & $26,09 \%$ \\
\hline Statement 2: Improved business-IT alignment & +4 & +3 & +2 & +3 & -4 & +4 & +4 & 0 & 0 & 6 & $34,80 \%$ \\
\hline Statement 23: Improved strategic agility & +4 & +2 & 0 & -2 & -5 & +2 & -3 & +1 & -5 & 4 & $17,40 \%$ \\
\hline $\begin{array}{l}\text { Statement } 36 \text { : Ability to unify and integrate data across } \\
\text { the enterprise }\end{array}$ & +4 & +1 & -4 & +2 & +1 & +1 & -2 & +2 & +5 & 5 & $21,80 \%$ \\
\hline
\end{tabular}

Table 6: Factor 2. Universal risk-tolerant pragmatist, key items

\begin{tabular}{|c|c|c|c|c|c|c|c|c|c|c|c|}
\hline Statement & $\mathrm{F} 1$ & F2 & F3 & $\mathrm{F} 4$ & F5 & F6 & F7 & F8 & F9 & $\begin{array}{c}\text { Total No. } \\
\text { Respondents }\end{array}$ & $\%$ \\
\hline Statement 4: Provides a holistic view of the enterprise & +5 & +5 & +5 & -1 & +1 & +3 & +4 & -4 & +5 & 10 & $43,50 \%$ \\
\hline Statement 10: Improved alignment with partners & -2 & +5 & -3 & -1 & +2 & -1 & 0 & -2 & 0 & 2 & $8,70 \%$ \\
\hline Statement 12: Increased standardization & 0 & +4 & +3 & 0 & -2 & +5 & +2 & 0 & -1 & 4 & $17,40 \%$ \\
\hline Statement 13: Improved business processes & 0 & +4 & +1 & +4 & +2 & 0 & +2 & +2 & -2 & 4 & $17,40 \%$ \\
\hline Statement 21: Increased reusability & -1 & +4 & +5 & 0 & -3 & +2 & +3 & +2 & +3 & 3 & $13,04 \%$ \\
\hline
\end{tabular}

Table 7: Factor 3. Evolutionary reuse overseer, key items

\begin{tabular}{|c|c|c|c|c|c|c|c|c|c|c|c|}
\hline Statement & $\mathrm{F} 1$ & $\mathrm{~F} 2$ & F3 & F4 & F5 & F6 & F7 & F8 & F9 & $\begin{array}{c}\text { Total No. } \\
\text { Respondents }\end{array}$ & $\%$ \\
\hline Statement 4: Provides a holistic view of the enterprise & +5 & +5 & +5 & -1 & +1 & +3 & +4 & -4 & +5 & 10 & $43,50 \%$ \\
\hline Statement 21: Increased reusability & -1 & +4 & +5 & 0 & -3 & +2 & +3 & +2 & +3 & 3 & $13,04 \%$ \\
\hline $\begin{array}{l}\text { Statement 16: Evolutionary EA development \& } \\
\text { governance }\end{array}$ & +3 & -2 & +4 & -4 & +3 & +2 & -3 & -1 & +1 & 1 & $4,35 \%$ \\
\hline Statement 31: Improved business use of technology & +2 & 0 & +4 & +5 & -3 & -1 & +3 & -3 & -4 & 3 & $13,04 \%$ \\
\hline Statement 37: Improved IT visibility & -2 & -1 & +4 & +1 & -2 & 0 & +1 & -5 & -2 & 1 & $4,35 \%$ \\
\hline
\end{tabular}

Table 8: Factor 4. Technology leverager, key items

\begin{tabular}{|c|c|c|c|c|c|c|c|c|c|c|c|}
\hline Statement & $\mathrm{F} 1$ & $\mathrm{~F} 2$ & F3 & F4 & F5 & F6 & F7 & F8 & F9 & $\begin{array}{c}\text { Total No. } \\
\text { Respondents }\end{array}$ & $\%$ \\
\hline Statement 31: Improve business use of technology & +2 & 0 & +4 & +5 & -3 & -1 & +3 & -3 & -4 & 3 & $13,04 \%$ \\
\hline $\begin{array}{l}\text { Statement 39: Closer partnership between business and } \\
\text { IT }\end{array}$ & +3 & +3 & +3 & +5 & +3 & +4 & -2 & -5 & -1 & 4 & $17,40 \%$ \\
\hline Statement 8: Increased quality & -3 & 0 & -2 & +4 & -1 & -1 & +3 & +3 & +1 & 2 & $8,70 \%$ \\
\hline Statement 13: Improved business processes & 0 & +4 & +1 & +4 & +2 & 0 & +2 & +2 & -2 & 2 & $8,70 \%$ \\
\hline Statement 40: Enable business intelligence & 0 & -3 & +1 & +4 & +4 & 0 & -4 & +2 & +2 & 3 & $13,04 \%$ \\
\hline
\end{tabular}

Table 9: Factor 5. Simplicity valuer, key items

\begin{tabular}{|c|c|c|c|c|c|c|c|c|c|c|c|}
\hline Statement & F1 & $\mathrm{F} 2$ & F3 & $\mathrm{F} 4$ & F5 & F6 & F7 & F8 & F9 & $\begin{array}{c}\text { Total No. } \\
\text { Respondents }\end{array}$ & $\%$ \\
\hline Statement 6: Increased economies of scale & -2 & -2 & -1 & -2 & +5 & +3 & +1 & +1 & -3 & 1 & $4,35 \%$ \\
\hline Statement 18: Reduced complexity & +3 & 0 & -5 & 0 & +5 & -2 & +4 & 0 & +1 & 3 & $13,04 \%$ \\
\hline Statement 5: Improved communication & -4 & +1 & -1 & +3 & +4 & -4 & +1 & -1 & +3 & 1 & $4,35 \%$ \\
\hline Statement 24: Improved staff management & -5 & -5 & -2 & -2 & +4 & -4 & -4 & 0 & -1 & 1 & $4,35 \%$ \\
\hline Statement 40: Enable business intelligence & 0 & -3 & +1 & +4 & +4 & 0 & -4 & +2 & +2 & 3 & $13,04 \%$ \\
\hline
\end{tabular}


Table 10: Factor 6. IT commoditiser, key items

\begin{tabular}{|c|c|c|c|c|c|c|c|c|c|c|c|}
\hline Statement & $\mathrm{F} 1$ & $\mathrm{~F} 2$ & F3 & $\mathrm{F} 4$ & F5 & F6 & F7 & F8 & F9 & $\begin{array}{c}\text { Total No. } \\
\text { Respondents }\end{array}$ & $\%$ \\
\hline Statement 12: Increased standardization & 0 & +4 & +3 & 0 & -2 & +5 & +2 & 0 & -1 & 4 & $17,40 \%$ \\
\hline Statement 14: Improved alignment to business strategy & +5 & -1 & -3 & -2 & 0 & +5 & -2 & 0 & +2 & 6 & $26,10 \%$ \\
\hline Statement 2: Improved business-IT alignment & +4 & +3 & +2 & +3 & -4 & +4 & +4 & 0 & 0 & 8 & $34,80 \%$ \\
\hline Statement 28: Improved IT governance & +2 & -1 & +1 & -1 & +2 & +4 & +5 & -1 & 0 & 4 & $17,40 \%$ \\
\hline $\begin{array}{l}\text { Statement 39: Closer partnership between business and } \\
\text { IT }\end{array}$ & +3 & +3 & +3 & +5 & +3 & +4 & -2 & -5 & -1 & 4 & $17,40 \%$ \\
\hline
\end{tabular}

Two $(8,7 \%)$ of the participants loaded significantly on Factor 7, which accounts for $6 \%$ of total variance and an eigenvalue of 1,33 (see Table 11). This factor is negatively loaded and as a result the statements were switched in order to identify the factor's true values.

Factor 8 (see Table 12) represents two participants $(8,7 \%)$, $4 \%$ of total variance and an eigenvalue of 0,82 . This factor is negatively loaded and as a result the statements were switched in order to identify the factor's true values.

Two of the participants, making up 8,7\% of all participants, $3 \%$ of the variance and an eigenvalue of 0,68 , were loaded on Factor 9 (see Table 13). This factor is negatively loaded and as a result the statements were switched in order to identify the factor's true values.

Three participants did not load significantly on any of the 9 factors, while 3 more participants were "confounded" as they loaded on more than 1 factor. Each of these groups represents $13,04 \%$ of all participants. The perceptions of these two groups did not coincide with those of other participants in the study to a level that could be considered significant, or their viewpoints were confused amongst the perceptions represented by more than one factor.

\section{Factor interpretation}

Factor 1 has been named Transformational Task-driven Strategists. The participants loading significantly on this factor believe in adjusting all parts of the organisation so that they fall into the appropriate relative positions. The belief is that once functional areas and IT (through EA) are congruent to the organisational strategy (statement 14, position +5 ), strategic agility (statement 23 , position +4 ) is improved. EA should provide overall planning in which processes, information and technology interoperate seamlessly to achieve the objectives of the business. Furthermore the right data should be made available to the right people at the right time (statement 36, position +4 ). The benefits of such a state are transformational, and can be considered to be so because these stakeholders articulate a direction which seeks to change the current situation. It provides the insights needed to address business requirements as well as facilitating the transition from strategy to execution. Transformational Task-driven Strategists bring order out of chaos; they are proactive; and they help determine how EA should be used. They view EA as an evolution of current and future operations in order to achieve organisational goals. EA exists at the level of abstraction and hides the complexities of the various components of the organisation (statement 18, position +3 ).

Factor 2 has been named Universal Risk-tolerant Pragmatist. The Universal Risk-tolerant Pragmatist believes in the universal applicability of EA in impacting the enterprise and its external environment in the form of its partners (statement 10, position +5 ). It is believed that it is easier for ICT to show the value that it adds by improving alignment with partners. A holistic view (statement 4, position +5 ) combined with standardisation (statement 12 , position +4 ) and reuse (statement 21, position +4 ) centre around the belief that with best practice, a universally applicable approach can be found. EA is viewed more as an instrument used by management, and is far broader than mere staff management. It is not viewed as a means of improving customer orientation as this is seen as the responsibility of business itself (statement 17, position -4). The universalistic approach seems to emphasis rules above relationships. Statement 10 distinguishes this factor from all others. Factor 2 is the only factor that identifies improved alignment with partners as a critical benefit of EA.

Factor 3 is named Evolutionary Reuse Overseer. The Evolutionary Reuse Overseer uses the holistic view of the enterprise (statement 4 , position +5 ) to increase reusability of processes (statement 21, position +5 ). He or she believes that EA gives a high level overview of the enterprise and each unit's responsibilities. Furthermore, processes can be used to adhere to new operations. EA is developed in an evolutionary manner (statement 16 , position +4 ). It is believed that the need to reduce complexity increases as the understanding of the enterprise increases (statement 18, position -5).

Factor 4 has been named Technology Leverager. Technology Leveragers believe in leveraging technology to improve the business. They are most likely to enquire how any technology is likely to improve business outcomes (statement 39, position +5), including business process (statement 13, position +4). Quality is likely to feature dominantly in such discussions (statement 8, position +4 ). The Technology Leverager least associates "Shortened cycle times" (statement 1, position -5), "Managerial satisfaction" (statement 33, position -5), and "Improving integration of mergers and acquisitions" (statement 29, position -4) with EA benefits. This enforces the view that EA is primarily about leveraging technology (statement 31 , position +5 ). 
Table 11: Factor 7. Operational stability maintainer, key items

\begin{tabular}{|c|c|c|c|c|c|c|c|c|c|c|c|}
\hline Statement & $\mathrm{F} 1$ & $\mathrm{~F} 2$ & $\mathrm{~F} 3$ & $\mathrm{~F} 4$ & F5 & F6 & F7 & F8 & F9 & $\begin{array}{c}\text { Total No. } \\
\text { Respondents }\end{array}$ & $\%$ \\
\hline Statement 20: Improved stability & +1 & -2 & 0 & +1 & 0 & -4 & +5 & -1 & -3 & 2 & $8,70 \%$ \\
\hline Statement 28: Improved IT governance & +2 & -1 & +1 & -1 & +2 & +4 & +5 & -1 & 0 & 2 & $8,70 \%$ \\
\hline Statement 2: Improved business-IT alignment & +4 & +3 & +2 & +3 & -4 & +4 & +4 & 0 & 0 & 8 & $34,80 \%$ \\
\hline Statement 4 : Provides a holistic view of the enterprise & +5 & +5 & +5 & -1 & +1 & +3 & +4 & -4 & +5 & 10 & $43,50 \%$ \\
\hline Statement 18: Reduced complexity & +3 & 0 & -5 & 0 & +5 & -2 & +4 & 0 & +1 & 3 & $13,04 \%$ \\
\hline
\end{tabular}

Table 12: Factor 8. Organisational change manager, key items

\begin{tabular}{|c|c|c|c|c|c|c|c|c|c|c|c|}
\hline Statement & $\mathrm{F} 1$ & $\mathrm{~F} 2$ & F3 & $\mathrm{F} 4$ & F5 & F6 & F7 & F8 & F9 & $\begin{array}{c}\text { Total No. } \\
\text { Respondents }\end{array}$ & $\%$ \\
\hline Statement 7: Improved change management & -1 & +1 & +2 & -3 & -2 & 0 & -2 & +5 & -3 & 2 & $8,70 \%$ \\
\hline $\begin{array}{l}\text { Statement 38: Reduced the impact that staff turnover has on } \\
\text { business }\end{array}$ & -5 & 0 & -2 & +2 & -1 & -2 & -5 & +5 & 0 & 2 & $8,70 \%$ \\
\hline Statement 11: Increased interoperability and integration & +3 & +2 & -4 & +1 & +3 & +3 & +1 & +4 & +3 & 2 & $8,70 \%$ \\
\hline Statement 26: Improved decision making & 0 & +3 & 0 & +3 & +1 & -3 & +3 & +4 & 0 & 2 & $8,70 \%$ \\
\hline Statement 34: Accelerate IT system implementation & +1 & +3 & +2 & +2 & +3 & -2 & +2 & +4 & -1 & 2 & $8,70 \%$ \\
\hline
\end{tabular}

Table 13: Factor 9. Siloed product manager, key items

\begin{tabular}{|c|c|c|c|c|c|c|c|c|c|c|c|}
\hline Statement & $\mathrm{F} 1$ & $\mathrm{~F} 2$ & $\mathrm{~F} 3$ & $\mathrm{~F} 4$ & F5 & F6 & F7 & F8 & F9 & $\begin{array}{c}\text { Total No. } \\
\text { Respondents }\end{array}$ & $\%$ \\
\hline Statement 4: Provides a holistic view of the enterprise & +5 & +5 & +5 & -1 & +1 & +3 & +4 & -4 & +5 & 10 & $43,50 \%$ \\
\hline $\begin{array}{l}\text { Statement 36: Ability to unify and integrate data across } \\
\text { the enterprise }\end{array}$ & +4 & +1 & -4 & +2 & +1 & +1 & -2 & +2 & +5 & 5 & $21,80 \%$ \\
\hline Statement 1: Shortened cycle times & -1 & 0 & -1 & -5 & -2 & -5 & 0 & -1 & +4 & 1 & $4,35 \%$ \\
\hline Statement 15: Improved asset management & -2 & -3 & -3 & 0 & -4 & +1 & -3 & -4 & +4 & 1 & $4,35 \%$ \\
\hline Statement 27: Improved innovation & -3 & -1 & -4 & +3 & 0 & -2 & 0 & -2 & +4 & 1 & $4,35 \%$ \\
\hline
\end{tabular}

Factor 5 has been named Simplicity Valuer. Simplicity Valuers consist of enthusiasts who fundamentally believe that complexity should be eliminated (statement 18 , position +5 ). They are focused on bottom-line effects (statement 6, position +5 ). Increased economies of scale make business sense to them, and they are likely to view EA purely as a support function, similar to the rest of IT, with no possibility of offering any competitive edge (statement 23, position -5 ; statement 25 , position -5 ; statement 9 , position -4 ). They typically consider IT as a black-hole where money gets thrown in with the generation of little value (statement 15, position -4). They are likely to use EA as a vehicle in ensuring that value is ultimately derived from IT investments (statement 5 , position +4 ). Factor 5 is the only factor which rates Item 2 as heavily negative while at the same time rating statements 6 and 24 as heavily positive. The combination of statements 6 and 24 emphasises the bottom-line focus of the participants. Improved staff management implies the drive for efficiency.

Factor 6 has been named IT Commoditiser. The IT Commoditiser believes that EA should be used to not only drive IT towards commoditisation through standardisation (statement 12 , position +5 ) but that this should be done within confines that ensure that deployment is aligned to business imperatives (statement 14 , position +5 ; statement 2 , position +4 ; statement 39 , position +5 ). Governance is viewed as a vehicle to ensure that all is undertaken in a transparent and visible manner (statement 28, position +4 ). EA cannot guarantee organisations' 'Increased market value" (statement 9, position -5). Furthermore, current EA approaches are not considered to contribute to "Improved communication" (statement 5, position -4). "Improved staff management" (statement 24, position -4) is considered to be a highly specialised function which is more suited to dedicated units such as Human Resources and as such no improvement can be achieved through any successful implementation of EA.

Factor 7 has been named Operational Stability Maintainer. The Operational Stability Maintainer utilises the holistic view (statement 4, position +4 ) to find the flaws of the whole, not just the flaws of the parts. IT Governance (statement 28 , position +5 ) is the primary vehicle used to 
ensure that this is achieved and that complexity is reduced (statement 18, position +4). The high positive rating of "Improved IT governance" (statement 28, +5) and "Reduced complexity", (statement 18, +4), when combined with "Provides a holistic view of the enterprise" (statement 4, position +4 ), could be a reflection of the maintenance-based mode and attitude of such participants towards risk avoidance. "Increased stability" (statement $20,+5$ ) is the only statement that distinguishes factor 7 from all other factors. Business intelligence (statement 40, position -4) is not associated positively with EA benefits, largely because business intelligence is considered a practice that should be entrenched through management practices. The organisation's market value (statement 9, position -4) is considered the responsibility of all functions within business and not purely that of EA. Factor 7 rates statement 20 as highly positive, and it is this statement ranking that makes factor 7 the most risk-averse ("stability maintainer") of the factors.

Factor 8 has been named Organisational Change Manager. An Organisational Change Manager views change as an integral part of the organisation that needs to be properly managed (statement 7 , position +5 ). This could be done in a manner which reduces any impact that staff turnover might have on the business (statement 38, position +5 ). IT systems implementation has to be accelerated (statement 34, position $+4)$ so that interoperability and integration can be accelerated. This in turn is expected to result in "Improved decision making" (statement 26, position +4). "Improved change management" (statement 7 , position +5 ) is the only statement that distinguishes factor 8 from all other factors. Factor 8 rates statement 7 far more positively that all the other factors, which is indicative of the importance and benefit associated with change management by participants who loaded on this factor.

Factor 9 has been named Siloed Product Manager. The Siloed Product Manager focuses on the delivery of products as indicated by "Shortened cycle times" (statement 1, position +4) without any consideration given to strategic agility (statement 23, position -5 ); or compliance to legislation (statement 30, position -5 ). The holistic view of the enterprise (statement 4 , position +5 ) could be considered to be achievable through the ability to unify and integrate data across the enterprise (statement 36 , position +5 ). This in turn could be expected to shorten cycle times (statement 1 , position +4 ), improve innovation (statement 27 , position +4) and improve asset management (statement 15, position $+4)$. The perspective of the Siloed Product Manager is narrowed down to the delivery of a specific product only. Statements 1 and 19 distinguish factor 9 from all the other factors. Factor 9 rates statement 1 highly whereas the other factors do not. Siloed Product Managers are focused on ensuring that their products are taken to market far quicker than those of competitors. The low rating of statement 19 in this factor indicates the weak link between the need for a holistic view relative to its impact on costs. This is the very reason why the factor is considered to be siloed.

\section{Discussion}

This study has explored the subjective perceptions of business stakeholders regarding the benefits of EA. There are no perceived EA benefits that are consistent across the different stakeholder segments, reinforcing two widely held views. The first is that EA benefits different stakeholders in different ways and the second is that stakeholder segmentation will contribute substantially towards entrenching EA. The study further contributes to the provision of an initial insight into the subset of EA stakeholders, as identified in the 9 factors that emerged in the research. Lastly, by identifying clearly defined stakeholder segments, the research offers a method for targeted EA benefits communications. EA initiatives can begin with the customisation of benefits to specific target stakeholders in order to ensure higher levels of success.

The study identifies a hierarchy of perceived EA benefits to an organisation. In terms of response, the following are the dominant perceptions that are seen to contribute significantly $(+5,+4)$ :

- Statement 4 Provides a holistic view of the enterprise (43.5\% of participants across all factors).

- Statement 2 Improved business-IT alignment (34.8\% of participants across all factors).

- Statement 14 Improved alignment to business strategy ( $27 \%$ of participants across all factors).

- Statement 36 Ability to unify and integrate data across the enterprise (21.8\% of participants across all factors).

- $\quad$ Five factors were jointly ranked $5^{\text {th }}$. Statement 23 Improved strategic agility; Statement 12 Increased standardisation; Statement 13 Improved business processes; Statement 39 Closer partnership between business and IT; and Statement 28 Improved IT governance (17.4\% of participants across all 9 factors).

This ranking does not reflect any shared meaning across factors or the shared contexts of these statements or the participants who hold them, but merely indicates the salience of these statements amongst the participants in this study. It should be noted that Q-methodology focuses on interrelations among persons with respect to a population of tests - therefore the salience of individual statements is not critical to the study or its overall conclusions (Donner, 2001). What can be drawn from the relative salience of these items is that EA benefits cannot be thought of in absolute terms. Their importance is very much dependent on the perspectives of the stakeholders under observation. The question "Which benefits do you consider most significant for EA?" has multiple answers. The answer is dependent on the stakeholder/participant being asked, and the relative position held by the stakeholder/participant relative to others.

The study has clearly identified nine stakeholder categories: Transformational Task-driven Strategist, Universal Risktolerant Pragmatist, Evolutionary Reuse Overseer, 
Technology Leverager, Simplicity Valuer, IT Commoditiser, Operational Stability Maintainer, Organisational Change Manager, and Siloed Product Manager. The categories identified in the study may be evident in the broader population of EA business stakeholders but further research is required to test the validity of the assumption.

\section{Recommendations, limitations \\ contributions \\ and}

The contribution of this study is primarily the identification of hitherto undefined EA stakeholder segments and their perceptions of EA benefits. The study clarifies the perceptions of EA by Telkom SA's different business stakeholders, and the contexts and logic of these perceptions. The findings represent dominant perceptions of EA at Telkom and cannot be extrapolated to industry as a whole. The categories may, however, be used as starting points in further research into EA stakeholder perceptions with the use of methodologies that are suited to the generalisation of findings. Improved stakeholder knowledge will provide EA practitioners with the necessary tools required in ensuring that targeted EA artefacts are developed, and further that more targeted communication messages are developed in the realm of EA. The question then arises whether marketing concepts will be more vigorously applied in the domain of EA than is currently the case.

Q-methodology is a powerful tool for the investigation of convergent subjective perceptions. While it has been in existence for close to 80 years, it has never been widely used because of the technical and mathematical difficulties in doing so. With recent developments in technology and the software to support it, its use may be expected to increase. Q-methodology offers the scientific rigour to test stakeholders' perceptions, and to cluster them so that rich groupings of perceptions and the people who hold them can emerge.

The following recommendations are drawn from the findings of this study:

- EA practitioners' mindsets must change: The technically led development of EA will limit its application. An all-inclusive approach to EA is now required with external stakeholders of ICT playing a central role in directing EA efforts. Organisations should build initiatives to incorporate the "voice of the customer". An ICT-centric approach to service delivery is likely to fail without a change in mindset.

- Benefit Segmentation must be incorporated into EA stakeholder definition: EA benefit needs should be used to segment EA stakeholders. It is evident in the study that different segments have significantly different expectations of the benefits sought from EA. Thus benefits sought should form segmentation variables for EA. EA practitioners can focus on those segments that are likely to tilt EA initiatives towards success.
- Application of Q methodology. The use of Qmethodology should be encouraged, particularly in the African leadership paradigm which encourages communalism, a high humane-orientation and emphasis on the value of the collective. Qmethodology ensures that subjective views are uncovered and grouped so that collective perspectives can emerge. The methodology can focus on the singular ("my preference") and the collective ("our preference") at the same time, an extremely useful attribute when attempting to develop a collective perspective.

The study has a number of limitations. The sample was too limited to allow extrapolation to the wider EA community, and while this was not an objective of the study, it should be pursued in further research. The Concourse in this study was primarily derived from the academic literature, opinion articles and EA practitioners, and not stakeholders, whose views are essential and may not yet be fully evident in academic sources. Limited researcher-participant interaction may have restricted the rich qualitative information that could have been derived through the opportunities afforded by Q-methodology. Additional insights may, for example, have been derived with follow-up interviews or focus groups to derive a greater understanding of the perceptions that were identified and the contexts in which they apply.

\section{Conclusion}

This study serves as an initial step in generating knowledge and understanding of Enterprise Architecture's stakeholder segments and their perception of EA. Currently the links between EA benefits and stakeholders is limited and a relatively new topic of study, but one that is vital in improving the adoption of EA within organisations. This study's identification of EA stakeholder segments should go a long way towards ensuring that greater understanding and better targeted communication occurs. The 9 factors identified in this study represent subjective perceptions of EA benefits that are the most important, albeit in one organisation. More generally, the study identifies a methodology that is suitable for the identification of EA benefits and the value in doing so. It also offers a range of critical benefits and the stakeholder segments that may be most closely associated with these benefits. The feelings that stakeholders have of Enterprise Architecture are unique, and as Stephenson (1980:356) puts it, "feelings are not a matter of mere words put into a certain order like pieces of a jigsaw puzzle, but far more, a new idea that cannot be described by any general formula." Perceptions of EA are new ideas, and it is hoped that this study contributes in describing them in the rich context that is made possible by the methodology of the study.

\section{References}

Amin, Z. 2000. 'Q methodology - A journey into the subjectivity of human mind', Singapore Medical Journal, 41(8): 410-414. 
Angelopulo, G. 2009. 'Q methodology and the measurement of subjectivity in corporate brand perception', South African Journal of Business Management, 40(3): 21-34.

Best, R.J. 2005. Market-based management: Strategies for growing customer value and profitability. Upper Saddle River, N.J.: Pearson/Prentice Hall.

Brown, S.R. 1980. Political subjectivity: Applications of $Q$ methodology in Political Science. New Haven, CT: Yale University Press.

Brown, S.R. 1991. 'Q methodology tutorial.' [online] URL: http://facstaff.uww.edu/cottlec/qarchive/qindex.htm.

Brown, S.R. 1993. 'A primer on Q methodology', Operant Subjectivity, 16(3/4): 91-138.

Brown, T. 2004. 'The value of enterprise architecture.' [online]

URL: http://www.modaf.com/file_download/19.

Buchanan, R.D. \& Soley, R.M. 2002. 'Aligning enterprise architecture and IT investments with corporate goals.' [online] URL:

http://citeseerx.ist.psu.edu/viewdoc/download?doi=10.1.1.1

$19.8264 \&$ rep $=$ rep $1 \&$ type $=$ pdf

Cardwell, G. 2008. 'The influence of enterprise architecture and process hierarchies on company success', Total Quality Management, 19(1/2): 47-55.

Chung, L., Song, H., Song, Y. \& Subramanian, N. 2009. 'Understanding the role of enterprise architecture towards better institutionalization'. Paper presented at the $10^{\text {th }}$ ACIS International Conference on Software Engineering, Artificial Intelligence, Networking and Parallel/Distributed Computing, 27-29 May 2009, Catholic University of Daegu, Daegu, Korea.

DeCoster, J. 1998. 'Overview of factor analysis'. [online] URL: http://www.stat-help.com/factor.pdf

De Vries, M. \& Van Rensburg, A.C.J. 2008. 'Enterprise architecture - New business value perspectives', South African Journal of Industrial Engineering, 19(1): 1-16.

Donner, J.C. 2001. 'Using Q-sorts in participatory processes: An introduction to the methodology', Social Development Papers, 36(June): 24-49.

Frederick, B.N. 1999. 'Factor analysis of people rather than variables: Q and other two-mode factor analytic models'. Paper presented at the Annual Meeting of the Southwest Educational Research Association, 23 January 1999, San Antonio, TX, USA.

Gremy, F., Fesler, F.M. \& Bonnin, M. 1999. 'Information systems evaluation and subjectivity', International Journal of Medical Informatics, 56(1-3): 13-23.

Harmon, K. 2005. "The "systems" nature of enterprise architecture'. Paper presented at the 2005 IEEE
International Conference on Systems, Man and Cybernetics, 10-12 October 2005, Waikoloa, HI, USA.

Harris, P.T. 2008. 'Enterprise architecture and its role in solving business issues: Case study of the NSW Department of Lands'. Paper presented at the 2008 IEEE $8^{\text {th }}$ International Conference on Computer and Information Technology Workshops, 8-11 July 2008, Sydney, Australia.

Hilliad, R. 2000. 'IEEE Standard 1471-2000: Recommended practice for architecture description of software-intensive systems.' [online] URL:

http://www.enterprise-

architecture.info/Images/Documents/IEEE\%2014712000.pdf.

Jonkers, H., Lankhorst, M.M., Ter Doest, H.W.L., Arbab, F., Bosma, H. \& Wieringa, R.J. 2006. 'Enterprise architecture: Management tool and blueprint for the organisation', Information Systems Frontiers, 8(2): 63-66.

Kamogawa, T. \& Okada, H. 2009. 'Enterprise architecture creates business value'. Paper presented at the $9^{\text {th }}$ Annual International Symposium on Applications and the Internet, 20-24 July 2009, Seattle, WA, USA.

Kappelman, L.A. (Ed.) 2010. The SIM guide to enterprise architecture. Boca Raton: CRC Press.

Kluge, C., Dietzsch, A. \& Rosemann, M. 2006. 'Fostering an enterprise architecture's value proposition using dedicated presentation strategies'. Paper presented at the $18^{\text {th }}$ Conference on Advanced Information Systems Engineering, 5-9 June 2006, Luxembourg.

Kowert, P.A. 1996. 'Where does the buck stop?: Assessing the impact of presidential personality', Political Psychology, 17(3): 421-452.

Liimatainen, K. 2008. 'Evaluating benefits of government enterprise architecture.' [online] URL:

http://www.iris31.se/papers/IRIS31-059.pdf.

Lindström, A., Johnson, P., Johansson, E., Ekstedt, M. \& Simonsson, M. 2006. 'A survey on CIO concerns - do enterprise architecture frameworks support them?', Information Systems Frontiers, 8(2): 81-90.

Malan, R., Bredemeyer, D., Krishnan, R. \& Lafrenz, A. 2006. Enterprise architecture as business capabilities architecture. [online] URL:

http://www.bredemeyer.com/pdf_files/Presentations/Enterpr iseArchitectureAsCapabilitiesArchSlides.PDF.

Matthee, M.C., Tobin, P.K.J. \& Van der Merwe, P. 2006. 'The status quo of enterprise architecture implementation in South African financial services companies', South African Journal of Business Management, 38(1): 11-23.

McKeown, B. \& Thomas, D. 1988. Q methodology. Newbury Park: Sage Publications. 
Niemi, E. 2006. 'Enterprise architecture benefits: Perceptions from literature and practice'. Paper presented at the $7^{\text {th }}$ IBIMA Conference on Internet \& Information Systems in the Digital Age, 14-16 December 2006, Brescia, Italy.

Nonaka, I. \& Toyama, R. 2005. 'The theory of the knowledge-creating firm: subjectivity, objectivity and synthesis', Industrial and Corporate Change, 14(3): 419436.

Pereira, C.M. \& Sousa, P. 2005. 'Enterprise architecture: Business and IT alignment'. Paper presented at the $20^{\text {th }}$ Annual ACM Symposium on Applied Computing, 13-17 March 2005, Socorro, NM, USA.

Plazaola, L., Flores, J., Vargas, N. \& Ekstedt, M. 2008. 'Strategic business and IT alignment assessment: A case study applying an enterprise architecture-based metamodel'. Paper presented at the $41^{\text {st }}$ Hawaii International Conference on Systems Sciences, 7-10 January 2008, Waikoloa, HI, USA.

Ross, J.W. 2003. 'Creating a strategic IT architecture competency: Learning in stages'. MIS Quarterly Executive, 2(1): 31-43.

Ross, J.W. \& Weill, P. 2005. 'Understanding the benefits of enterprise architecture', CISR Research Briefings. Massachusetts: Massachusetts Institute of Technology.

Ross, J.W., Weill, P., \& Robertson, D.C. 2006. Enterprise architecture as strategy: Creating a foundation for business execution. Boston: Harvard Business School Press.

Sexton, D., Snyder, P., Wadsworth, D., Jardine, A. \& Ernest, J. 1998. 'Applying Q methodology to investigations of subjective judgments of early intervention effectiveness', Topics in Early Childhood Special Education, 18(2): 95107.

Shwu-Ing Wu. 2001. 'Benefit segmentation: An empirical study for on-line marketing', Asia Pacific Journal of Marketing and Logistics, 13(4): 3-18.

Steelman, T.A. \& Maguire, L.A. 1999. 'Understanding participant perspectives: Q-methodology in national forest management', Journal of Policy Analysis and Management, 18(3): 361-388.

Stephenson, W. 1980. 'Newton's fifth rule and Qmethodology: Application to educational psychology', American Psychologist, 35(10): 882-889.
Strano, C. \& Rehmani, Q. 2007. 'The role of the enterprise architect', Information Systems and e-Business Management, 5(4): 379-396.

Talbott, A.D. 1971. 'Q technique and its methodology: A brief introduction and consideration'. Paper presented at the Annual Meeting of the American Educational Research Association, 1 February 1971, New York, NY, USA.

Telkom. 2010. 'Corporate profile - Telkom Group’. [online] URL:

http://www.telkom.co.za/about_us/downloads/TELKOMcorporate-profile.pdf.

VandenBosch, D. 2001. 'Why do we factor variables when we care about types of people? Q and other two-mode factor analytic models', Paper presented at the annual meeting of the Southwest Educational Research Association, 1-3 February 2001, New Orleans, LA, USA.

Van der Raadt, B. \& Van Vliet, H. 2008. 'Designing the enterprise architecture function'. In Becker, S., Plasil, F. \& Reussner, R. (Eds.). Quality of software architectures: Models and architectures. Berlin: Springer-Verlag.

Van der Raadt, B., Schouten, S. \& Van Vliet, H. 2008. 'Stakeholder perception of enterprise architecture'. In Morrison, R., Balasubramaniam, D. \& Falkner, K. (Eds.). Software architecture. Berlin: Springer-Verlag.

Van Exel, J. \& De Graaf, G. 2005. 'Q methodology: A sneak preview'. [online]

URL: http://www.qmethod.org/articles/vanExel.pdf.

Webler, T., Danielson, S. \& Tuler, S. 2009. 'Using Q method to reveal social perspectives in environmental research'. [online] URL: www.serius.org/plus/Qprimer.pdf.

Weill, P. \& Ross, J.W. 2009. IT Savvy: What top executives must know to go from pain to gain. Boston: Harvard Business School Press.

Wilkins, H. 2003. 'The need for subjectivity in EIA: discourse as a tool for sustainable development', Environmental Impact Assessment Review, 23(4): 401-414.

Zachman, J.A. 1987. 'A framework for information systems architecture', IBM Systems Journal, 26(3): 276-292. 